\title{
Factors Affecting Complementary Feeding Pattern in
}

\section{Alexandria}

\author{
Sally Ezzat*
}

ABSTRACT: The nutritional needs of infants and young children change rapidly and their eating pattern progresses from breast milk and formula to more varied diets initiated by complementary feeding. Inappropriate feeding pattern is a major cause of the onset of malnutrition. The mother is responsible for the initiation, timing, and composition of complementary foods. This study was carried out to evaluate the impact of maternal factors on complementary feeding in Alexandria. The sample included 360 mothers of children in the age group 6-24 months attending the well baby Clinic in 3 $\mathrm{MCH}$ centers in Alexandria. Each mother was privately interviewed using a structured questionnaire to collect the needed data. The results show that $50-60 \%$ of the mothers derived their information about complementary feeding from family and friends, while $32.2 \%$ relied on the health team. More than $60 \%$ of the infants received complementary feeding before the age of 4 months, dairy products were the major complementary food $(51.9 \%)$ followed by cereals $(23.3 \%)$. The majority of the children $(45.0 \%)$ were given 3 meals daily while $21.9 \%$ were given two meals only. The foods were prepared for every meal $(68.6 \%)$, once daily $(25.3 \%)$ or every two days $(6.1 \%)$. Spicy, fatty, and sweetened foods are omitted from the infants' food. The results show that maternal factors such as the level of education of the mother, her employment status, and age had a clear significant effect on the source of information regarding complementary feeding, age at introducing food and the type used, meal frequency, and types of foods omitted.

\section{INTRODUCTION}

Nutrition is an important component of the child's health. A child's physical, cognitive, and emotional growth and development depend largely on the quantity, type of foods eaten, and the timing of introducing different food items.

During the first two years after birth, the nutritional needs of infants and toddllers change rapidly, and their eating patterns progress from simple diets of breast milk and formula to more varied diets that include juices, cereals, and solid foods. During this time, they form eating habits that may affect their later nutrition and health. ${ }^{(1)}$ Inappropriate feeding practices are a major cause of the onset of 
malnutrition in infants and young children who are at increased risk of malnutrition from six months of age onwards; when breast milk alone is no longer sufficient to meet all nutritional requirements. ${ }^{(2)}$ Malnutrition is responsible, directly or indirectly, for over half of all childhood deaths. It is estimated that $25 \%$ of all childhood deaths could be prevented by intervention to improve breast feeding and complementary feeding. ${ }^{(3,4)}$

In 2003, the WHO and PAHO jointly defined complementary feeding as the process starting when breast milk alone is no longer sufficient to meet the nutritional requirements of infants, and therefore other foods and liquids are needed along with breast milk. ${ }^{(5)}$ Complementary foods should be started when the baby can no longer get enough energy and nutrients from breast milk alone. For most babies this is at six months of age. This is also the age when nerves and muscles in the mouth are developed sufficiently to let the baby munch, bite, and chew. ${ }^{(6)}$

Formula may provide all nutrients needed for the first year of life, but it does not provide flavors, textures, and the opportunity to learn eating skills, which are important for formula fed as well as breast fed infants. ${ }^{(7)}$ A child receives less protective factors than in breast milk, so the risk of illness especially diarrhoea increases because complementary foods may not be as clean as breast milk. Types of food given instead of breast milk are often thin, watery porridge or soup as they are easier for babies to eat. These foods fill the stomach but provide fewer nutrients than breast milk, and so the child's needs are not met. ${ }^{(6)}$

During the period of transition from exclusive breast feeding to the cessation of breast feeding, infants gradually become accustomed to eating family foods until they entirely replace breast milk. Children are physically capable of consuming family foods by one year of age, after which 
should not be modified to meet special needs of the infants. ${ }^{(8)}$

Guiding principles of WHO in educating the mothers regarding complementary feeding practices of their breast-fed infants stated that the mother can practice good hygiene and proper food handling by washing caregivers' and child's hands before food preparing and eating, storing food safely, preserving food immediately after preparation, and using clean utensils to prepare and serve food.(9) The education of the mothers is considered to have a great impact on infants' nutritional status. The more a mother is knowledgeable the more she shall be able to help her child to grow nutritionally healthy as a young adult. ${ }^{(10)}$ Complementary feeding practices of infants and young children are often inadequate in developing countries.(11) Egypt is no exception, the results of studies carried out in Cairo(12) and Kaliobia(13) indicated that complementary feeding practices were not optimum.
Complementary feeding practices are influenced by many factors such as parental education, dietary beliefs, and behavior. $^{(14)}$

The aim of this study was to evaluate the impact of maternal factors on complementary feeding practices in Alexandria.

\section{MATERIAL AND METHODS}

The study was conducted at Maternal and Child Health centers (MCH) in Alexandria Governorate. The study included mothers accompanying their breast-fed children in the age group 6-24 months attending the well baby clinic at the $\mathrm{MCH}$ centers.

The study was implemented in three districts namely, Moharram Beck, ElGomorok and Semuha. One $\mathrm{MCH}$ center was randomly selected from each district and from each center a sample of 120 mothers was taken using a systematic random sample technique.

A structured questionnaire interview 
sheet was used to collect required information through a direct interview with mothers. The data included data on mothers age, working status and their level of education. The mothers were questioned about the sources of information regarding complementary feeding of children. Data were collected about mothers' practices while feeding their children including infant age at introducing complementary feeding, type of complementary food used, meal frequency at age 6-12 months, frequency of preparing meals and foods forbidden during complementary feeding.

Data were verified and analyzed using SPSS version 12.0 for Windows software package. The Chi squared test was used to compare the difference between variables. $P$ values of less than 0.05 were considered statistically significant.

\section{RESULTS}

The impact of mother's education, work, and age on the sources of information regarding complementary feeding of infants is presented in Table (1). The data show that $50.6 \%$ of the mothers derived their information from relatives and friends, $32.2 \%$ from the health team, and $17.2 \%$ from the mass media. The source of information varied significantly with mother's education $\left(X^{2}=37.77, p<0.001\right)$. University graduates were mostly informed through the health team (57.5\%). Illiterate and mothers with primary school education were mostly informed through relatives and friends, $60 \%$ and $52.5 \%$, respectively.

Mothers' work had a significant effect on the sources of information $\left(X^{2}=26.73\right.$, $\mathrm{p}<0.001$ ), working mothers were usually informed through the health team (41.7\%) while family and friends were the main source of information for non-working mothers (62.9\%). The sources of information were also significantly modified by mother's age. $\left(X^{2}=26.37, p<0.001\right)$. Young mothers aged less than 25 years were informed by the members of the health team $(45.5 \%)$ while mothers older 
than 35 years were informed at a months $(66.5 \%)$, this was significantly significantly higher rate by their relatives higher $\left(X^{2}=14.42, p<0.001\right)$ than among and friends $(66.6 \%)$. working mother (52.8\%). The results also

The factors affecting the age of introduction of complementary feeding is presented in Table (2). The results show that complementary foods were introduced by $60.3 \%$ of the mother when the infants were younger than 4 months, $21.1 \%$ between the age of 4 and 6 months, and $18.6 \%$ when the infants age was 6 months or older. The data show that $73.0 \%$ of the illiterate mothers introduced complementary foods when the infants age was less than 4 months as compared with $43.8 \%$ of the university graduates. The difference was statistically significant $\left(X^{2}=\right.$ 35.02, $p<0.01)$. The mean age of introducing complementary foods varied from 3.18 months among illiterate mothers to $4.38 \pm 2.40$ months among university graduates. Non-working mothers were keen to introduce complementary foods when the infant's age was less than 4 show that mothers younger than 25 years introduced complementary food when the infants were older than 6 months at a significantly high rate $\left(X^{2}=40.23, p<0.001\right)$ than among mothers whose age was more than 35 years, $29.8 \%$ and $6.5 \%$, respectively. The mean age at introducing complementary foods for both groups were $4.60 \pm 2.5$ and $2.68 \pm 1.66$ months, respectively.

The results presented in Table (3) show that the types of complementary foods offered to infants varied with several maternal factors. University educated mothers offered cereals at a significantly higher rate $(37.0 \%)$ than illiterate mothers (14.6\%). The latter group used dairy products $(53.9 \%)$ or fluids $(21.3 \%)$ at higher rate than mothers with middle level or university education. The differences were statistically significant $\left(X^{2}=28.48\right.$, 
$p<0.01)$. Vegetables soup was offered at a comparable rate by mother from all educational levels. The data show that working mothers offered cereals at a high rate $(32.5 \%)$ when compared to nonworking mothers (15.7\%). The latter group used fluids, vegetable group, and dairy products at a significantly higher rate than working mothers $\left(X^{2}=15.55, p<0.01\right)$. The age of the mother did not have a significant effect on the type of complementary foods used. However, mothers older than 35 years used dairy products and vegetable soup at a relatively high rate, $58.1 \%$ and $17.2 \%$, respectively, while mothers younger than 25 years offered cereals at a relatively high rate $(30.6 \%)$.

Table (4) illustrates the factors affecting the frequency of meals offered to infants in the age group 6-12 months. The results show that $4.2 \%$ and the infant were offered one meal daily, $21.9 \%$ two meals, $45.0 \% 3$ meals, and $28.9 \%$ were given more than 3 meals. The frequency of meals varied significantly with mothers education $\left(\mathrm{X}^{2}=\right.$ $35.35, p<0.001)$. University graduate gave their infants either two or three meals daily, $32.9 \%$ and $49.3 \%$. The corresponding rates for illiterate mother were $13.5 \%$ and $38.2 \%$, respectively. Mother from the latter group offered the infant 3 or more meals daily at a higher rate $(42.7 \%)$ when compared with university graduates (13.6\%). The mean number of meals decreased from $3.18 \pm 0.87$ among illiterate mothers to $2.73 \pm 0.75$ among university graduates. Non-working mothers offered their children 3 or more meals at a higher rate $(32.5 \%)$ than working mothers $(24.5 \%)$ who offered their children 2 or 3 meals daily, $28.8 \%$ and $41.1 \%$, respectively. The differences were statistically significant $\left(X^{2}\right.$ $=15.55, \mathrm{p}<0.01)$. The same trend was observed with old mother who gave their infants 3 or more meals daily at a significantly high rate $(37.6 \%)$ than mothers younger than 25 years $(21.6 \%) \quad\left(X^{2}=\right.$ $13.81, p<0.05)$, the latter group offered the 
infants two meals daily at a significantly higher rate $(29.1 \%)$. The mean number of meals increased from $2.81 \pm 0.84$ among mothers younger than 25 years to $3.20 \pm 0.75$ when the mothers were older than 35 years.

The frequency of preparing complementary foods is presented in Table (5). The results show that $68.6 \%$ of the mothers prepared the food every meal, $25.3 \%$ once daily, and $6.1 \%$ of the meals were prepared every two days. Although the frequency of preparing the meals was not significantly modified by the education, the work and the age of the mothers, it was noted the foods were prepared every meal at a relatively high rate by illiterate mothers (74.2\%), non-working mothers (77.2\%) and mothers younger than 25 years $(70.2 \%)$. The highest rate of preparing the meals once daily was reported by working mothers (33.7\%) and mother older than 35 years $(31.1 \%)$.

The types of food forbidden during complementary feeding infant is illustrated in Table (6). The data show that the most common forbidden foods were spicy foods $(35.3 \%)$, fatty foods (27.2\%), and sweetened foods (11.9\%), while $25.6 \%$ of the mother reported that they did not know of any forbidden foods. The type of forbidden foods varied significantly with mothers' education $\left(X^{2}=27.56 \%, p<0.01\right)$. Spicy foods and fatty foods were forbidden by university graduates at a significantly high rate $(38.4 \%$ and $34.2 \%)$ when compared with illiterate mothers, 29.2\% and $20.2 \%$, respectively. The lack of knowledge about forbidden foods was highest among illiterate mothers (41.6\%). The results show that spicy and fatty foods were forbidden at a significantly high rates $\left(X^{2}=47.83, p<0.001\right)$ by working mothers $40.5 \%$ and $37.4 \%$, respectively. The corresponding rates for non working mothers, were $31.0 \%$ and $18.0 \%$, respectively. The results also show that spicy and fatty foods were forbidden by 
older mother $(39.8 \%$ and $34.4 \%)$ at a as they will determine the accuracy of the significantly higher rates $\left(X^{2}=18.73\right.$, information received. The results of this $p<0.01)$ than mothers younger than 25 years, $29.1 \%$ and $24.6 \%$, respectively.

\section{DISCUSSION}

Adequate nutrition during infancy and early childhood is fundamental to the development of each child's full potential. Appropriate complementary feeding practices lead to improved nutrition and physical growth and reduces susceptibility to childhood infections. The complementary feeding patterns of infants and young children are modified by several interacting factors. Since the mother is the person who usually decides if complementary foods will be introduced to the child, at what age and which types of foods are used, this study describes the impact of maternal factors on complementary feeding pattern of infants and young children.

The sources of information about complementary feeding are very important study revealed that relatives and friends were the most important source of information about complementary feeding of children (50.6\%) while the health team was the source of information for $32.2 \%$ of the mothers. This would lead to passing faulty habits and practices from one mother to the others.

The sources of information varied as university graduate, young, and working mothers were likely to resort to the health team to derive information about complementary feeding of their children (Table 1). It is evident that the level of education and awareness of the mothers were very important determinants of their sources of information. It was of interest to note that $60.3 \%$ of the mothers introduced complementary feeding when the infant age was less than 4 months; another $18.6 \%$ started feeding when the infant was older than 6 months. Those rates are higher than 
the corresponding rates reported in Egypt Demographic Health Survey (2005) which reported that $20.7 \%$ of breast-fed infants were given water-based liquids or juices at the age of $0-3$ months and $16.6 \%$ of them were given these fluids at the age of $4-6$ months. ${ }^{(15)}$

The available data are quite contradictory. In a previous study implemented more than 14 years ago (1995) in Alexandria, it was reported that $40 \%$ of infants in the age group 2-3 months were given complementary foods. ${ }^{(16)}$ In Giza, a higher rate $(65.4 \%)$ of early introduction of complementary foods in rural area was reported in 1992. This may be attributed to the ignorance of the mother about the sound practices of introducing complementary feeding. ${ }^{(17)}$

UNICEF (1998) advocated for starting complementary feeding at the age of 6 months.(18) Egypt adopted this strategy since 2003. ${ }^{(19)}$ However the results of this study confirmed that the channel of education failed to convey this message to mothers.

The results showed that early introduction of complementary feeding was associated with mothers' illiteracy, work, and relatively older age. A larger proportion of well educated mothers who were mostly working derived their information from the health team, started complementary feeding at the age between 4 and 6 months (Table 2). Educated mothers have better knowledge about the nutritional requirements of their children as well as the necessary income to purchase the foods they need. (20)

In Ismalia, it was reported that early complementary feeding was significantly higher among mothers with university degree. Early introduction of complementary feeding was also more common among employed mothers. ${ }^{(21)}$ It has been frequently reported in developing countries that early introduction of complementary feeding is associated with 
low level of mothers' education.(22)

Dairy products were commonly used as a complementary food by illiterate nonworking mothers who assumed that such products would supplement their breast milk and would meet the infants' requirements. Educated, working mothers who have better knowledge about complementary feeding used cereals as a complementary food. However, it was reported that Children whose mothers had a college education were more likely to consume fruits and less likely to consume sweetened beverages and deserts. ${ }^{(23)}$

The use of low calorie fluids such as anise, caraway, and belela water was associated with mothers' illiteracy, such foods will not contribute to improving the nutrition of the infant or meeting his requirements (Table 3 ) and will render the child more susceptible to malnutrition.

WHO (2003) recommended that for the average healthy breast-fed children, meals of complementary foods should be provided 2-3 times daily at the age of $9-11$ months. ${ }^{(5)}$ The number of times that a child is fed complementary foods should be increased as he/she gets older. For the average healthy breast-fed infant, meals of complementary foods should be provided 2-3 times per day at 6-8 months of age, and 3-4 times per day at 9-11 months of age. Additional nutritious snacks (as a piece of fruit or bread) may be offered 1-2 times per day or as desired.(24) The data presented in (Table 4 ) show that $45.0 \%$ of the mothers offered the child 3 complementary meals daily. Those were mostly educated, working mothers who would not hindered by their working hours from offering the children the required meals. It was also noted that illiterate and non-working mothers who are fully devoted to their homes offered more than 3 complementary meals at a significantly high rate when compared with other groups. The same trend was noted with young mothers who were more keen to 
offer more meals to their children (Table 4). feeding practices. The results show that The frequency of preparing meals is a while $25.6 \%$ of the mothers did not know function of the time the mother can devote about any foods that should be omitted for her child. The majority of the mothers during complementary feeding, university $(68.6 \%)$ prepared complementary food graduates were more likely to omit spicy, every meal. They preferred to offer the fatty, and sweetened foods at a higher rate. child fresh meal, however working mothers were more likely to prepare the Such practice was followed by working mothers and those older than 35 years and complementary food once daily and divide have adequate experience about breast it to portions to be given afterwards (Table feeding (Table 6).

5). It was surprising to note that $6.1 \%$ of The limited knowledge of the illiterate the mothers prepared the meals every two non-working mothers about foods that days which may increase the possibility of should be omitted during complementary its contamination if not stored under cooled feeding and that may be harmful to the hygienic conditions.

children points out that such groups should

The types of foods forbidden during be the target of nutrition education complementary feeding reflects the level of programs that could be implemented knowledge of the mothers about the sound through $\mathrm{MCH}$ centers and mass media. 
Table (1): Impact of mothers' education, work and age on the source of information regarding complementary feeding of children

\begin{tabular}{|c|c|c|c|c|c|c|c|c|}
\hline & \multicolumn{6}{|c|}{ Source of information } & \multirow{2}{*}{\multicolumn{2}{|c|}{ Total }} \\
\hline & \multicolumn{2}{|c|}{ Health team } & \multicolumn{2}{|c|}{ Mass media } & \multicolumn{2}{|c|}{ Relatives and friends } & & \\
\hline & No. & $\%$ & No. & $\%$ & No. & $\%$ & No. & $\%$ \\
\hline \multicolumn{9}{|l|}{ Mothers' education } \\
\hline Illiterate & 13 & 14.6 & 22 & 24.7 & 54 & 60.6 & 89 & 24.7 \\
\hline Primary/Preparatory & 30 & 30.9 & 16 & 16.4 & 51 & 52.5 & 97 & 26.9 \\
\hline Secondary & 31 & 30.7 & 13 & 12.9 & 57 & 56.4 & 101 & 28.1 \\
\hline \multirow[t]{2}{*}{ University } & 42 & 57.7 & 11 & 15.1 & 20 & 27.3 & 73 & 20.3 \\
\hline & \multicolumn{8}{|c|}{$\mathrm{X} 2=37.77$} \\
\hline \multicolumn{9}{|l|}{ Mothers' work } \\
\hline Working & 68 & 41.7 & 37 & 22.7 & 58 & 35.6 & 163 & 45.3 \\
\hline \multirow[t]{2}{*}{ Not working } & 48 & 24.4 & 25 & 12.7 & 124 & 62.9 & 197 & 54.7 \\
\hline & \multicolumn{8}{|c|}{$X 2=26.73$} \\
\hline \multicolumn{9}{|l|}{ Mother's age (years) } \\
\hline$<25$ & 61 & 45.5 & 24 & 17.9 & 49 & 36.6 & 134 & 37.2 \\
\hline $25-35$ & 41 & 30.8 & 21 & 15.8 & 71 & 53.3 & 133 & 37.0 \\
\hline$>35$ & 14 & 15.1 & 17 & 18.2 & 62 & 66.6 & 93 & 25.8 \\
\hline \multirow[t]{2}{*}{ Total } & 116 & 32.2 & 62 & $\overline{17.2}$ & 182 & 50.6 & 360 & 100 \\
\hline & \multicolumn{8}{|c|}{$X 2=26.37}$, \\
\hline
\end{tabular}


Table (2): Factors affecting the age of the infant at introducing complementary feeding

\begin{tabular}{|c|c|c|c|c|c|c|c|c|c|}
\hline & \multicolumn{6}{|c|}{$\begin{array}{l}\text { Infants' age at introducing } \\
\text { complementary foods (months) }\end{array}$} & \multirow{2}{*}{\multicolumn{2}{|c|}{ Total }} & \multirow{3}{*}{$X_{ \pm \mathrm{SD}}$} \\
\hline & \multicolumn{2}{|c|}{$<4$} & \multicolumn{2}{|c|}{ 4-6 } & \multicolumn{2}{|c|}{$6+$} & & & \\
\hline & No. & $\%$ & No. & $\%$ & No. & $\%$ & No. & $\%$ & \\
\hline \multicolumn{10}{|l|}{ Mothers' education } \\
\hline Illiterate & 65 & 73.0 & 13 & 14.6 & 11 & 12.4 & 89 & 24.7 & $3.18 \pm 2.10$ \\
\hline Primary/Preparatory & 74 & 76.3 & 12 & 12.4 & 11 & 11.3 & 97 & 26.9 & $3.05 \pm 2.03$ \\
\hline Secondary & 46 & 45.5 & 27 & 26.7 & 28 & 27.7 & 101 & 28.1 & $4.47 \pm 2.50$ \\
\hline \multirow[t]{2}{*}{ University } & 37 & 43.8 & 24 & 32.9 & 17 & 23.3 & 73 & 20.3 & $4.38 \pm 2.40$ \\
\hline & \multicolumn{8}{|c|}{$\mathrm{X} 2=35.02$} & \\
\hline \multicolumn{10}{|l|}{ Mothers' work } \\
\hline Working & 86 & 52.8 & 49 & 30.1 & 28 & 17.7 & 163 & 45.3 & $3.93 \pm 2.2$ \\
\hline \multirow[t]{2}{*}{ Not working } & 131 & 66.5 & 27 & 13.7 & 39 & 19.8 & 197 & 54.7 & $3.60 \pm 2.4$ \\
\hline & \multicolumn{8}{|c|}{$\mathrm{X} 2=14.42$} & \\
\hline \multicolumn{10}{|l|}{ Mother's age (year) } \\
\hline$<25$ & 58 & 43.3 & 36 & 26.9 & 40 & 29.8 & 134 & 37.2 & $4.60 \pm 2.5$ \\
\hline $25-35$ & 81 & 60.9 & 31 & 23.3 & 21 & 15.8 & 133 & 37.0 & $3.65 \pm 2.2$ \\
\hline$>35$ & 78 & 838 & 9 & 9.7 & 9 & 6.5 & 93 & 25.8 & $2.68 \pm 1.66$ \\
\hline \multirow[t]{2}{*}{ Total } & 217 & 60.3 & 76 & 21.1 & 67 & 18.6 & 360 & 100 & \\
\hline & \multicolumn{8}{|c|}{$\mathrm{X} 2=40.23$} & \\
\hline
\end{tabular}


Table (3): Types of complementary foods and its variation with mothers' education, work and age

\begin{tabular}{|c|c|c|c|c|c|c|c|c|c|c|}
\hline & \multicolumn{8}{|c|}{ Type of complementary foods } & \multirow{2}{*}{\multicolumn{2}{|c|}{ Total }} \\
\hline & \multicolumn{2}{|c|}{ Fluids } & \multicolumn{2}{|c|}{ Cereals } & \multicolumn{2}{|c|}{$\begin{array}{c}\text { Dairy } \\
\text { products }\end{array}$} & \multicolumn{2}{|c|}{$\begin{array}{l}\text { Vegetables } \\
\text { and soup }\end{array}$} & & \\
\hline & No. & $\%$ & No. & $\%$ & No. & $\%$ & No. & $\%$ & No. & $\%$ \\
\hline \multicolumn{11}{|l|}{ Mothers' education } \\
\hline Illiterate & 19 & 21.3 & 13 & 14.6 & 48 & 53.9 & 9 & 10.1 & 89 & 24.7 \\
\hline Primary/Preparatory & 13 & 13.4 & 15 & 15.5 & 51 & 52.6 & 18 & 18.6 & 97 & 26.9 \\
\hline Secondary & 6 & 5.9 & 29 & 28.7 & 53 & 52.5 & 13 & 12.9 & 101 & 28.1 \\
\hline \multirow[t]{2}{*}{ University } & 5 & 6.8 & 27 & 37.0 & 35 & 44.9 & 6 & 9.5 & 73 & 20.3 \\
\hline & \multicolumn{10}{|c|}{$\mathrm{X} 2=28.48, \quad \mathrm{p}<0.01$} \\
\hline \multicolumn{11}{|l|}{ Mothers' work } \\
\hline Working & 14 & 8.6 & 53 & 32.5 & 79 & 48.5 & 17 & 10.4 & 163 & 45.3 \\
\hline \multirow[t]{2}{*}{ Not working } & 29 & 14.7 & 31 & 15.7 & 108 & 54.8 & 29 & 14.7 & 197 & 54.7 \\
\hline & \multicolumn{10}{|c|}{$X 2=15.55, \quad p<0.01$} \\
\hline \multicolumn{11}{|l|}{ Mother's age (year) } \\
\hline$<25$ & 16 & 11.9 & 41 & 30.6 & 68 & 56.8 & 9 & 6.7 & 134 & 37.2 \\
\hline $25-35$ & 12 & 9.0 & 35 & 26.3 & 65 & 48.9 & 21 & 15.8 & 133 & 37.0 \\
\hline$>35$ & 15 & 16.1 & 8 & 8.6 & 54 & 58.1 & 16 & 17.2 & 93 & 25.8 \\
\hline \multirow[t]{2}{*}{ Total } & 43 & 11.9 & 84 & 23.3 & 187 & 51.9 & 46 & 12.8 & 360 & 100 \\
\hline & \multicolumn{10}{|c|}{$X 2=21.67$} \\
\hline
\end{tabular}


Table (4): Impact of maternal factors on meal frequency at age 6-12 months

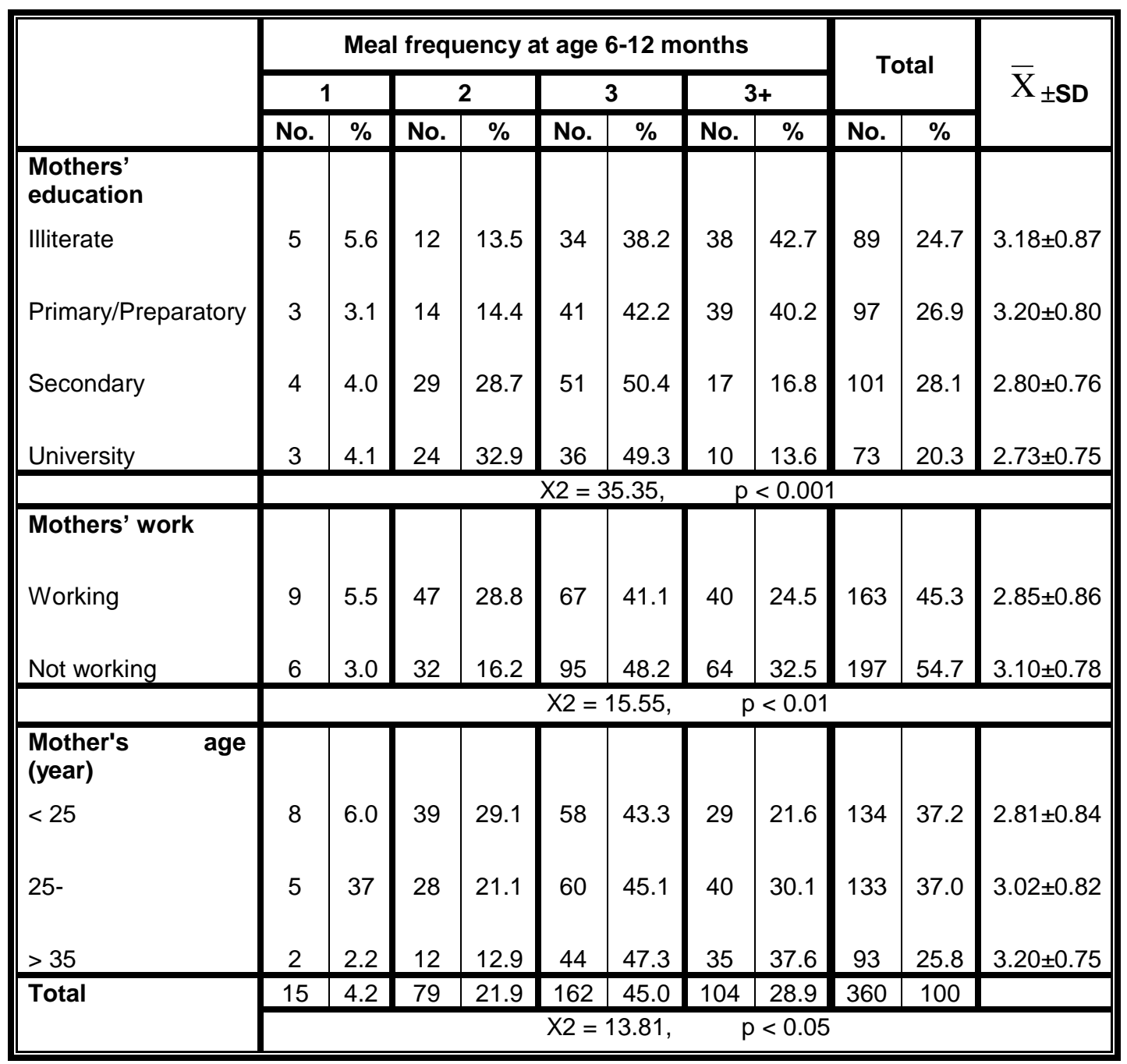


Table (5): Frequency of preparing complementary foods offered to infant at age 6-12 months

\begin{tabular}{|c|c|c|c|c|c|c|c|c|}
\hline & \multicolumn{6}{|c|}{ Frequency of preparing meals } & \multirow{2}{*}{\multicolumn{2}{|c|}{ Total }} \\
\hline & \multicolumn{2}{|c|}{ Every meal } & \multicolumn{2}{|c|}{ Once daily } & \multicolumn{2}{|c|}{$\begin{array}{l}\text { Every two } \\
\text { days }\end{array}$} & & \\
\hline & No. & $\%$ & No. & $\%$ & No. & $\%$ & No. & $\%$ \\
\hline \multicolumn{9}{|l|}{ Mothers' education } \\
\hline Illiterate & 66 & 74.2 & 18 & 20.2 & 5 & 5.6 & 89 & 24.7 \\
\hline Primary/Preparatory & 69 & 71.1 & 22 & 22.7 & 6 & 6.2 & 97 & 26.9 \\
\hline Secondary & 65 & 64.3 & 30 & 29.7 & 6 & 5.9 & 101 & 28.1 \\
\hline \multirow[t]{2}{*}{ University } & 42 & 64.4 & 21 & 28.7 & 5 & 6.9 & 73 & 20.3 \\
\hline & \multicolumn{6}{|c|}{$\mathrm{X} 2=4.15$} & & \\
\hline \multicolumn{9}{|l|}{ Mothers' work } \\
\hline Working & 195 & 58.2 & 55 & 33.7 & 13 & 8.0 & 163 & 45.3 \\
\hline \multirow[t]{2}{*}{ Not working } & 152 & 77.2 & 36 & 18.2 & 9 & 4.6 & 197 & 54.7 \\
\hline & \multicolumn{6}{|c|}{$\mathrm{X} 2=14.77$} & & \\
\hline \multicolumn{9}{|l|}{ Mother's age (year) } \\
\hline$<25$ & 94 & 70.2 & 31 & 23.1 & 9 & 6.7 & 134 & 37.2 \\
\hline $25-35$ & 95 & 71.4 & 31 & 23.3 & 7 & 5.3 & 133 & 37.0 \\
\hline$>35$ & 58 & 62.3 & 29 & 31.1 & 6 & 6.5 & 93 & 25.8 \\
\hline Total & 247 & 68.6 & 91 & 25.3 & 22 & 6.1 & 360 & 100 \\
\hline
\end{tabular}


Table (6): Types of foods forbidden during complementary feeding

\begin{tabular}{|c|c|c|c|c|c|c|c|c|c|c|}
\hline & \multicolumn{8}{|c|}{ Forbidden foods } & \multirow{2}{*}{\multicolumn{2}{|c|}{ Total }} \\
\hline & \multicolumn{2}{|c|}{$\begin{array}{l}\text { Spicy } \\
\text { foods } \\
\end{array}$} & \multicolumn{2}{|c|}{$\begin{array}{l}\text { Fatty } \\
\text { foods }\end{array}$} & \multicolumn{2}{|c|}{$\begin{array}{l}\text { Sweetened } \\
\text { foods }\end{array}$} & \multicolumn{2}{|c|}{$\begin{array}{l}\text { Do not } \\
\text { know }\end{array}$} & & \\
\hline & No. & $\%$ & No. & $\%$ & No. & $\%$ & No. & $\%$ & No. & $\%$ \\
\hline \multicolumn{11}{|l|}{ Mothers' education } \\
\hline Illiterate & 26 & 29.2 & 18 & 20.2 & 8 & 9.0 & 37 & 41.6 & 89 & 24.7 \\
\hline Primary/Preparatory & 39 & 40.2 & 19 & 19.6 & 11 & 11.3 & 28 & 28.9 & 97 & 26.9 \\
\hline Secondary & 34 & 33.7 & 36 & 35.6 & 13 & 12.9 & 18 & 17.8 & 101 & 28.1 \\
\hline \multirow[t]{2}{*}{ University } & 28 & 38.4 & 25 & 34.2 & 11 & 15.1 & 9 & 12.3 & 73 & 20.3 \\
\hline & \multicolumn{10}{|c|}{$\mathrm{X} 2=27.56$} \\
\hline \multicolumn{11}{|l|}{ Mothers' work } \\
\hline Working & 66 & 40.5 & 61 & 37.4 & 22 & 13.5 & 14 & 8.6 & 163 & 45.3 \\
\hline \multirow[t]{2}{*}{ Not working } & 61 & 31.0 & 37 & 18.8 & 21 & 10.6 & 78 & 39.6 & 197 & 54.7 \\
\hline & \multicolumn{8}{|c|}{$X 2=47.83$} & & \\
\hline \multicolumn{11}{|l|}{ Mother's age (year) } \\
\hline$<25$ & 39 & 29.1 & 33 & 24.6 & 13 & 9.7 & 49 & 36.6 & 134 & 37.2 \\
\hline $25-35$ & 51 & 30.3 & 34 & 25.6 & 16 & 12.0 & 32 & 24.1 & 133 & 37.0 \\
\hline$>35$ & 37 & 39.8 & 32 & 34.4 & 14 & 15.1 & 10 & 10.7 & 93 & 25.8 \\
\hline \multirow[t]{2}{*}{ Total } & 127 & 35.3 & 98 & 27.2 & 43 & 11.9 & 92 & 25.6 & 360 & 100 \\
\hline & \multicolumn{10}{|c|}{$\mathrm{X} 2=18.73$} \\
\hline
\end{tabular}




\section{REFERENCES}

1. Devaney B, Kalb L, Briefel R, Zavitsky-Novak T, Clusen N, Ziegler $P$. Feeding Infants and Toddlers study: Overview of the study design. J Am Diet Assoc. 2004; 104: S8-S13.

2. WHO. Collaborative study team on the role of breast-feeding on the prevention of child mortality due to infectious diseases in developing countries: a pooled analysis. Lancet. 2000; 355: 451-5.

3. WHO. Complementary feeding: Report of the global consultation \& summary of guiding principles for complementary feeding of the breastfed child. Geneva: WHO; 2001. p. 110.

4. Daelmans B, Saadeh R. Global initiatives to improve complementary feeding. Standing Committee on Nutrition (SCN NEWS). 2003; 27: 10-8.

5. Pan American Health Organization/World Health Organization. Guiding principles for complementary feeding of the breastfed child. Washington, DC: Pan American Health Organization; 2003.

6. WHO. Complementary feeding: Family foods for breastfed children. Geneva: WHO; (WHO/FCH/00.6); 2000. p. 151.

7. Butte N, Cobb K, Dwyer J, Graney L, Heird W, Richard K. The start healthy feeding guidelines for infants and toddlers. J Am Diet Assoc. 2004; 104 : 442-53.

8. Michaelsen KF, Weaver L, Branca F, Robertson A. Feeding and nutrition of infants and young children: guidelines for the WHO European Region with emphasis on the former Soviet Countries. Regional Office for Europe: WHO and UNICEF; 2004. p. 180-197.
9. WHO. Five keys to safer food. Geneva: WHO;

(WHO/SDE/PHE/F05/01.1); 2001.

10. Smith L, Haddad L. Explaining child malnutrition in developing countries. Across country analysis. Washington D.C: Research Report. International Food Policy Research Institute; 2000.

11. Samina SH. Weaning practices in peri-urban low socioeconomic groups. J Coll Physicians Surg Pak. 2005; 15(3): 129-32.

12. Eman ML, El-Mougi M, Hafez AS. A study of knowledge, attitude and practices of Egyptian mothers towards weaning. Egypt J Comm Med. 1991; 8(1): 119-27.

13. Abd El-Rahman HA, Mohamed TA, Shoulah AR, El-MosImani AM. Beliefs and traditional practices affecting nutritional status in infancy at Kaliobia Governorate. Egypt J Comm Med. 1994; 12(2)8: 81-7.

14. Sritharan N, Morgan J. Complementary feeding for the full term infant. In: Morgan JB, Dickerson JWT, (eds). Nutrition in Early Life. England: John Wiley; 2003. pp. 233 255.

15. El-Zanaty F. Egypt Demographic Health Survey. Egypt: Ministry of Health and Population. National Population Council; 2005.

16. El-Sahn FF, Kharboush IF, Nasseir SA. Use of breast feeding indicators for assessment of current feeding practices. J Egypt Public Hth Assoc. 1995; LXX(3,4): 307-22.

17. Hakim JA, El-Ashmawy IA. Breastfeeding pattern in rural village in Giza. Am J Pub Leth. 1992; 82(5): 731-42.

18. UNICEF. The state of the world's children. 1998. UNICEF: Oxford University Press. 1998: 9-31.

19. Arab Republic of Egypt. Ministry of Health and Population, Primary Health Care Sector. General Administration 
of Childhood Program. Integrated management of childhood illness. The road to healthy childhood. Three years of Egyptian experience. 2003. 1-52.

20. Amine EK, Al-Awady FA. Nutritional status survey of preschool children in Kuwait. East Medit H J. 1996; 2(3): 386-95.

21. Al-Murshed K, Fiala LA, Abdel-Gawad ES, Atwa HA. Breast-feeding and complementary feeding in Egypt and Kingdom of Saudi Arabia. Bull H Instit Pub Hlth. 2004; 34(4): 895-912.

22. Perez ER, Lutter $C$, Segall $A$, Revera A, Treevino A, Sanghui T. Exclusive breast feeding duration is associated with attitudinal socioeconomic and biocultural determinants in the Latin American countries. J Nutr. 1995; 125(12): 2972-84.
23. Hendricks $\mathrm{K}$, Briefel $\mathrm{K}$, Novak $\mathrm{T}$, Ziegler P. Maternal and child characteristics associated with infants and toddlers feeding practices. J Amer Dietet Assoc. 2006; 106(Suppl 1): S136-47.

24. Daelmans B, Martines J, Saadeh R. Conclusions of the goals of consultations on complementary feeding. Food and Nutrition Bulletin of High Institute of Public Health. 2003; 24(1): 126-9.

25. Hendricks $K$, Briefel $R$, Novak $T$, Ziegler $P$. maternal and child characteristics associated with infants and toddlers feeding practices. Current Research Supplement. J Am Diet Assoc. 2006; 106(1): S135-48. 